Cad. Est. Ling., Campinas, 53(1), Jan./Jun. 2011

\title{
REPRESENTAÇÕES DE IDENTIDADES RACIAIS EM CAPAS DA REVISTA RAÇA BRASIL: UM ESTUDO À LUZ DA GRAMÁTICA DO DESIGN VISUAL
}

\author{
VIVIANE SEABRA PINHEIRO - UFMG* \\ CÉLIA MAGALHÃES - UFMG**
}

\begin{abstract}
RESUMO: No contexto brasileiro, tem havido um crescente interesse pelo uso da gramática do design visual (KRESS e VAN LEEUWEN, 1996) como método de análise eficaz para uma abordagem semiótica social. O presente trabalho, desenvolvido no âmbito do projeto CORDIALL da FALE/UFMG, busca contribuir para essa abordagem, a partir da análise de representações de identidades raciais em capas da revista Raça Brasil. O principal objetivo é investigar mudanças nos significados evocados pelas estruturas representacionais na imagem da capa das edições de novembro de 1996, 1998, 2004 e 2006 da referida publicação. A análise aponta para significados representacionais distintos ao longo de 10 anos de publicação da revista.
\end{abstract}

Palavras-chave: gramática do design visual, identidades raciais, revista Raça Brasil

\begin{abstract}
In the Brazilian context, the Grammar of the Visual Design (KRESS \& VAN LEEUWEN, 1996) has been increasingly applied as an efficient methodology to a social semiotic approach. This paper aims at contributing to this approach, by means of analyzing the representations of racial identities in covers of the magazine Raça Brasil. This research aims mainly at investigating changes in Representational meanings constructed through the visual component in the covers of 1996, 1998, 2004 and 2006 November editions of the magazine. The analysis points to different representational meanings in the corpus throughout a 10 -year temporal cline.
\end{abstract}

Keywords: Grammar of the Visual Design, racial identities, magazine Raça Brasil

\section{INTRODUÇÃO}

O presente trabalho apresenta uma análise das representações construídas pela imagem na capa de quatro edições da revista Raça Brasil. A pesquisa desenvolveu-se no âmbito do projeto CORDIALL (Corpus Discursivo para Análises Lingüísticas e Literárias) da FALE/ UFMG e faz, para efeitos do escopo do artigo, referência aos resultados de investigação que analisou os significados construídos pelo componente visual e por chamadas em capas de edições da revista Raça (PINHEIRO, 2007). O objetivo principal é investigar mudanças nos significados evocados pelas estruturas representacionais na imagem da capa das edições de novembro de 1996, 1998, 2004 e 2006 da referida publicação. A escolha de edições do mês de novembro justifica-se por ser este o mês em que se comemora o dia da consciência negra no Brasil, a partir 1995. Já a escolha dos referidos anos de publicação da revista leva em consideração o fato de 1996 ser o ano de lançamento da revista e de, juntamente com 1998, representar um período inicial de edição de Raça e

${ }^{*}$ UFMG, Belo Horizonte (MG), Brasil. vivyseabra@yahoo.com.br

${ }^{* *}$ UFMG, Belo Horizonte (MG), Brasil. celiamag@gmail.com 
de serem os números de 2004 e 2006 representativos de período mais recente à época da investigação, de modo que seria possível avaliar a existência de mudança discursiva com relação à questão racial ao longo dos anos. O suporte teórico-metodológico adotado para a análise das imagens é uma das abordagens que integram a Semiótica Social: trata-se da gramática do design visual proposta por Gunther Kress e Theo van Leeuwen (1996), mais especificamente no que se refere à sua abordagem das estruturas representacionais. Tal abordagem, desenvolvida com base nos princípios da Lingüística Sistêmico-Funcional, tem se mostrado eficiente na investigação de significados socialmente construídos. Usando tal aparato, busca-se responder às seguintes perguntas de pesquisa: (1) como o modo semiótico visual atua na construção das representações de identidades raciais nas capas sob análise? (2) há mudanças em tais significados ao longo do eixo temporal analisado? Os resultados da pesquisa apontam para significados representacionais distintos no corpus ao longo de 10 anos de publicação da revista.

Este trabalho é apresentado em quatro seções distintas. Na primeira seção, é feita uma exposição do referencial teórico-metodológico que dá suporte ao estudo; na segunda, apresentam-se o corpus e a metodologia para sua análise; na terceira, analisam-se e discutem-se os dados obtidos por meio do procedimento de análise adotado e, finalmente, apresentam-se os resultados e considerações finais da pesquisa.

\section{REFERENCIAL TEÓRICO}

A Semiótica Social, escola de semiótica à qual os teóricos utilizados neste estudo - e conseqüentemente o próprio estudo - se afiliam, tem início na Austrália, a partir dos trabalhos de M. A. K. Halliday (1978, dentre outros), que concebem a linguagem como semiótica social, isto é, como um recurso com o qual se constroem significados orientados para desempenhar funções em contextos sociais. A partir dessa concepção, é desenvolvida a gramática sistêmico-funcional, que define as três metafunções da linguagem: a ideacional, relacionada com a representação da experiência; a interpessoal, referente ao estabelecimento de interação; e a textual, relativa à construção de textos coerentes e relevantes. A abordagem semiótica social da comunicação visual proposta por Kress e van Leeuwen (1996) assume que o visual, assim como o verbal e todos os outros modos semióticos, serve a determinados propósitos, realizando trabalhos semióticos específicos. Entende-se que o visual realiza as mesmas 'tarefas' representacionais, interativas e de composição de textos definidas pela gramática sistêmico-funcional para o modo semiótico verbal. Assim, baseando-se no modelo inicial de Semiótica Social de Hodge e Kress (1988), Kress e van Leeuwen (1996) adaptam as metafunções ideacional, interpessoal e textual definidas por Halliday para a análise de imagens e composições visuais, passando a falar, então, de estruturas representacionais, de significados interativos e da composição.

O presente artigo, conforme exposto anteriormente, tem como foco a análise das estruturas representacionais na imagem em cada uma das capas da revista Raça Brasil que compõem o corpus deste trabalho. Destarte, na seção que segue, apresenta-se uma breve revisão dos pressupostos teóricos básicos da abordagem da gramática do design visual no que concerne às estruturas representacionais. 


\subsection{As estruturas representacionais}

Segundo Kress e van Leeuwen (1996), a sintaxe do visual cria significados. Isso quer dizer que, dentro do código semiótico das imagens, é possível representar o mesmo aspecto do mundo de forma diferente, de acordo com a escolha de determinada configuração, de certa estrutura visual. De acordo com Jewitt e Oyama (2001), essa escolha é sintomática dos discursos que regulam as representações construídas. Entendem-se 'discursos' na perspectiva de van Leeuwen (2005), que, com base no trabalho de Foucault, os define como "conhecimentos socialmente construídos de algum aspecto da realidade" (VAN LEEUWEN, 2005:94). Desse modo, como apontam Kress e van Leeuwen (1996), tais representações não são acidentais, mas estão vinculadas aos interesses das instituições que produzem e veiculam as imagens, ou seja, envolvem questões ideológicas.

Para a análise das imagens, a gramática do design visual introduz o termo 'participantes representados'. Isso porque este, além de incluir a questão do engajamento, ressalta o fato de existirem dois tipos de participantes em todo ato semiótico: os participantes interativos e os participantes representados. Os primeiros são aqueles que se comunicam por meio dos textos - o produtor da imagem ou do texto verbal e o observador ou leitor -; enquanto os segundos são aqueles que são retratados na imagem ou no texto verbal, quer sejam coisas, lugares ou pessoas.

As estruturas representacionais, de acordo com Kress e van Leeuwen (1996), subdividem- se em estruturas narrativas e conceituais. As primeiras apresentam ações e eventos, enquanto as segundas representam participantes em termos de sua essência: de sua classe, estrutura ou significado.

O que caracteriza uma proposição narrativa visual é a presença de um vetor, de um traço que indique direcionalidade. De acordo com o tipo de vetor e com o número de participantes envolvidos no evento, é possível distinguir seis tipos de processos narrativos: os processos de ação, os processos reacionais, os processos de fala e mentais, os processos de conversão e o simbolismo geométrico.

Nos processos de ação, o Ator é o participante de quem parte o vetor ou, em certos casos, ele próprio é o vetor. Ele geralmente é o participante mais proeminente nas figuras, seja pelo seu tamanho, posicionamento, contraste com o segundo plano, cor, foco e/ou 'saliência psicológica'. Esta se refere ao fato de determinados participantes atraírem a atenção do observador, como é o caso da figura humana ou, mais precisamente, de seu rosto (KRESS e VAN LEEUWEN, 1996).

Nas proposições narrativas visuais em que há apenas um participante envolvido, de modo que a ação não é dirigida a nenhum outro participante, a estrutura é chamada de não transacional. Já no caso de haver dois participantes, aquele a quem se dirige o vetor será a Meta, e a estrutura é chamada de transacional. Segundo Kress e van Leeuwen (1996), as estruturas transacionais podem ser bidirecionais; nestas, cada um dos participantes desempenha ora o papel de Ator, ora o papel de Meta. Neste último caso, os participantes são chamados de Inter-atores (Interactors).

Quando a direção do olhar de participantes representados forma um vetor, tem-se um processo reacional, e, nesse caso, esse participante é chamado de Reator (Reacter) e deve ser humano ou humanizado. Assim como no caso das ações, as reações podem ser 
transacionais ou não-transacionais. As reações transacionais se dão quando é possível observar o alvo do olhar, o que configura a existência de um segundo participante, o Fenômeno, que pode ser tanto outro participante quanto outra proposição visual.

Outro tipo de vetor pode ser encontrado nos balões que representam falas ou pensamentos de personagens, situação que configura a existência de um processo de fala ou de um processo mental. Tais processos conectam um participante animado, o Dizente no caso dos processos verbais e o Experienciador no caso dos processos mentais, a determinado conteúdo: ao que é falado, o Enunciado (Utterance), ou pensado, o Fenômeno.

Quando se tem uma cadeia de processos transacionais, surge outro tipo de participante, o Transmissor (Relay). Este desempenha o papel de Ator em relação a um participante e de Meta em relação a outro. O Transmissor não apenas retransmite, mas também modifica a mensagem que recebe. Nos casos em que se tem uma representação cíclica, todos os participantes são Transmissores. Tais processos são chamados, em Kress e van Leeuwen (1996), de processos de conversão.

Além dos tipos de processos mencionados, Kress e van Leeuwen (1996) conceituam ainda um último tipo de representação, o simbolismo geométrico, realizado, por exemplo, por meio de vetores em forma de hélices. O trabalho citado menciona também o fato de as estruturas narrativas poderem incluir participantes secundários, os quais não se relacionam aos participantes principais por meio de vetores: são as Circunstâncias. Estas podem ser de três tipos: Locativas, as quais situam participantes em relação a um cenário; de Meios, indicando ferramentas usadas para a realização de processos de ação; ou de Acompanhamento, que ocorrem quando um participante simplesmente acompanha outro, de forma que não se identifica um vetor que os relacione.

A FIG. 1 resume as distinções possíveis no que diz respeito às estruturas narrativas.

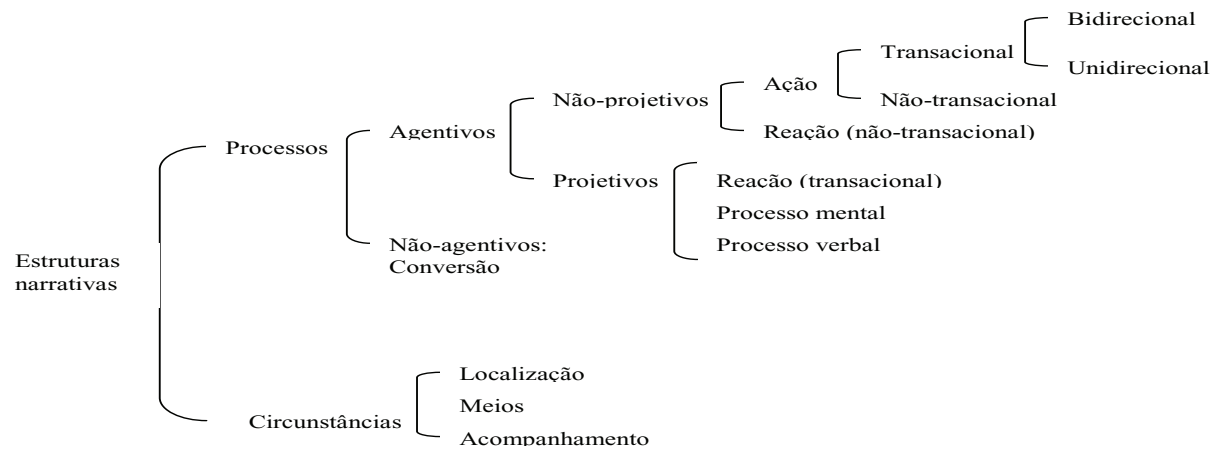

FIGURA 1 - Estruturas narrativas na comunicação visual Fonte: KRESS e VAN LEEUWEN, 1996: $73^{1}$

\footnotetext{
${ }^{1}$ A tradução da rede de sistemas é de responsabilidade do grupo de pesquisa a que se afiliam as autoras.
} 
As estruturas conceituais, que representam os participantes em termos de sua 'essência', podem ser construídas por meio de três tipos de processos: os processos classificacionais, os processos analíticos e os processos simbólicos. Os primeiros relacionam os participantes em termos de uma taxonomia. Nesse caso, deve haver pelo menos um participante Superordenado (Superordinate) em relação a outros, que serão os Subordinados (Subordinates).

As taxonomias podem ser fechadas ou abertas. Tem-se uma taxonomia fechada quando somente é possível identificar o Superordenado por meio do texto que acompanha a imagem ou por meio de inferência, a partir das similaridades dos Subordinados. Além disso, um traço distintivo das taxonomias fechadas é o fato de a equivalência entre os Subordinados se realizar na imagem por meio de uma composição simétrica; e, para conferir um caráter estável à classificação, os participantes são apresentados de forma objetiva e descontextualizada. Já no caso das taxonomias abertas, os Superordenados são explicitamente indicados. Elas ocorrem, por exemplo, em diagramas 'de árvore' e, geralmente, são multiniveladas, de modo que um participante intermediário, o Interordenado (Interordinate), é Subordinado em relação a determinados participantes e Superordenado em relação a outros, e os participantes no mesmo nível são apresentados como pertencentes à mesma classe. Kress e van Leeuwen (1996) mencionam também os diagramas classificacionais, que representam a relação entre os participantes representados em termos de um sistema.

No caso dos processos analíticos, a relação entre participantes é representada segundo uma estrutura de parte e todo, sendo um deles o Portador (o todo) e o(s) outro(s) o(s) Atributo(s) Possessivo(s) (as partes). Kress e van Leeuwen (1996) ressaltam que, pelo fato de uma análise sempre implicar seleção, de acordo com os interesses do analista, há a possibilidade de o mesmo Portador ser analisado em termos de Atributos distintos. Nesse tipo de processo, apresentam-se somente os traços essenciais dos Atributos Possessivos, que geralmente são nomeados. Desse modo, em tais representações, a profundidade, as cores e o segundo plano, por exemplo, são minimamente explorados ou mesmo nulos. Conforme apontam Kress e van Leeuwen (1996), as representações analíticas são definidas em termos negativos: caracterizam-se pela ausência dos traços característicos das outras formas de representação. Os processos analíticos são, assim, a opção de representação não-marcada: segundo a teoria, realizam um 'isso é' visual. Kress e van Leeuwen (1996) afirmam que mesmo certas fotografias de pessoas podem ser analíticas, especialmente quando essas pessoas posam para a foto. Outras representações que podem ser consideradas desse tipo são mapas e diagramas, fotografias aéreas e científicas e trabalhos de arte abstrata.

Os processos analíticos se dividem em alguns tipos que, por sua vez, são detalhados em subtipos. Para os fins do trabalho ora proposto, não serão apresentadas as subcategorias desse tipo de processo. Desse modo, os processos analíticos serão classificados de acordo com os tipos principais nas imagens em que estes se aplicarem (cf. KRESS e VAN LEEUWEN, 1996: 89-108, para uma visualização completa das estruturas analíticas).

Kress e van Leeuwen (1996) categorizam ainda um terceiro tipo de processo conceitual: os processos simbólicos. Nestes, participantes são representados em termos do que significam ou são, e, neste ponto, a gramática do design visual baseia-se na iconografia (JEWITT e OYAMA, 2001: 144). Tais processos se subdividem em atributivos 
ou sugestivos. Nos primeiros, há dois participantes: o Portador, "o participante cujo significado ou identidade é estabelecido na relação", e o Atributo Simbólico, "o participante que representa o próprio significado ou identidade" (KRESS e VAN LEEUWEN, 1996: 108). Como características dos Atributos Simbólicos, a gramática do design visual define a saliência, que pode ser realizada de formas diversas, como por meio de um tamanho exagerado ou de um posicionamento em primeiro plano; a presença de um gesto cuja função é tão-somente a de apontá-los para o observador; o seu aparente não-pertencimento ao conjunto da imagem e/ou sua associação a valores simbólicos. Participantes humanos envolvidos nesse tipo de processo, segundo a teoria, geralmente posam para o observador, de modo que sua postura não constitui uma estrutura narrativa.

Já no caso dos processos sugestivos, há apenas um participante, o Portador, sendo que o significado simbólico deste é estabelecido por meio da mistura de cores, da suavidade do foco ou da acentuação da luminosidade, o que faz com que apenas o contorno ou a silhueta dos participantes seja apresentada. O valor simbólico aferido ao Portador é determinado pelo modo como se dá o obscurecimento dos detalhes. Desse modo, enquanto nos processos atributivos a identidade ou o significado do Portador é a ele atribuído, no caso dos processos sugestivos, tal identidade ou significado é apresentado como um traço intrínseco ao Portador, como sua essência.

Na FIG. 2, resumem-se os principais tipos de estruturas conceituais.

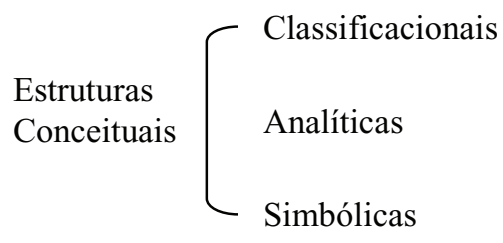

FIGURA 2 - Estruturas conceituais nas imagens

Fonte: Adaptada de KRESS e VAN LEEUWEN, 1996: 56

Concluindo a categorização das estruturas representacionais, Kress e van Leeuwen (1996) ressaltam que as imagens podem apresentar uma estrutura complexa, envolvendo mais de um processo e, portanto, mais de um nível estrutural.

Jewitt e Oyama (2001) apontam outros dois aspectos não abordados por Kress e van Leeuwen (1996) e que, segundo aquele trabalho, situam-se no âmbito dos significados representacionais, quais sejam, o cenário das imagens e a aparência visual dos participantes representados naquelas. Entende-se, no entanto, que a questão do cenário é contemplada, ao menos no que diz respeito às estruturas narrativas, quando se definem as Circunstâncias Locativas.

${ }^{2}$ MCCRACKEN, E. Decoding women's magazines - from mademoiselle to ms. Basingstoke: Macmillan, 1993. 


\section{CORPUS E METODOLOGIA}

\subsection{Do corpus}

O corpus deste trabalho é composto por capas de edições de novembro da revista Raça Brasil, uma publicação com periodicidade mensal direcionada ao público negro e atualmente produzida pela Editora Escala. A revista dirige-se, mais especificamente, a "homens e mulheres de classe A/B/C, dos 20 aos 49 anos", conforme o site da Editora Símbolo, anterior responsável pela publicação. A escolha da revista Raça Brasil foi determinada pelo interesse em se abordar, a partir da perspectiva da Lingüística Aplicada, um produto midiático segmentado do ponto de vista racial que, ao contrário de outros, sobrevive há mais de dez anos no mercado. A razão da escolha da capa está no interesse em se investigar os significados construídos por esta que, segundo McCracken² (apud Heberle, 2004: 102), atua como uma espécie de "lente interpretativa da edição" (e, argumenta-se, da postura da própria publicação), posicionando o público a quem se dirige favoravelmente quanto ao seu conteúdo. Entende-se que a análise do componente visual da capa faz-se indispensável, visto que o modo semiótico visual, assim como o verbal e concomitantemente a este, veicula significados, os quais são socialmente motivados e, portanto, atravessados por ideologias e relações de poder (KRESS, LEITE-GARCÍA e VAN LEEUWEN, 1997). Além disso, ressalte-se o fato de que é crucial o papel das imagens na sociedade contemporânea, visto que estas entram na constituição da maioria dos textos que circulam na mídia - que são, cada vez mais, multimodais.

Para que se pudesse analisar e comparar as representações construídas pela revista ao longo de 10 anos, desde o seu lançamento em 1996, decidiu-se por investigar uma edição desse ano e uma edição de 1998, representativas de uma fase inicial da publicação, e uma edição dos anos de 2004 e 2006, representativas de um período mais recente. Além de se tratar do ano de lançamento da revista, o ano de 1996 é significativo por ser aquele que sucedeu ao ano em que se comemorou o tricentenário da morte de Zumbi dos Palmares, líder da resistência do Quilombo de Palmares contra a opressão portuguesa na segunda metade do século XVII. Nesse mesmo ano de 1996, instaurou-se o dia 20 de novembro, dia da morte de Zumbi, como o dia da consciência negra. Assim, a seleção das edições do mês de novembro se deu justamente por ser este o mês de celebração da consciência negra, de modo que seria pertinente investigar as representações construídas nesse contexto.

A seguir, apresenta-se a metodologia adotada no desenvolvimento do presente trabalho. Nessa seção, explicita-se como foi feita a análise das capas das edições de Raça que constituem o corpus.

\subsection{Da metodologia}

Antes da descrição da metodologia de análise, cumpre ressaltar que a presente pesquisa é informada por uma leitura crítica da questão racial no contexto discursivo brasileiro mais amplo, em que se discutem noções como a ideologia do branqueamento, da democracia racial e de racismo cordial, discursos hegemônicos no país em conflito com discursos mais recentes de ações afirmativas e de valorização da herança cultural 
africana para os negros brasileiros (cf. MAGALHÃES, 2004, 2006). Tal discussão será aqui referida, quando necessário.

O primeiro passo para a realização deste trabalho foi a seleção do corpus, que se deu segundo os critérios já apontados na seção 3.1. Concluída essa seleção, o passo seguinte foi a digitalização do corpus: as capas das edições de novembro da revista Raça Brasil nos anos de 1996, 1998, 2004 e 2006 foram, então, escaneadas. Tais capas encontram-se reproduzidas na terceira seção, quando de suas respectivas análises.

Em seguida, deu-se início à etapa descritiva da pesquisa, aplicando-se ao componente visual das capas das edições do corpus o instrumental proposto por Kress e van Leeuwen (1996) para a análise dos significados representacionais em imagens - o qual se encontra apresentado na seção 2.1. Analisaram-se, então, os recursos que realizam os significados representacionais. Para tanto, identificou-se o tipo de estrutura representacional: se narrativa, indicada pela presença de vetores, e/ou conceitual, indicada pela classificação de participantes representados como pertencentes a determinado grupo, pela ênfase de Atributos desses participantes ou pela atribuição de valores simbólicos a elementos na imagem. No caso de identificação de uma estrutura narrativa, verificou-se o(s) tipo(s) de processo(s) realizado(s) imageticamente, por meio da observação do tipo de vetor e dos participantes. Já no caso de identificação de uma estrutura conceitual, rotularam-se o(s) processo(s) como classificacionais, analíticos ou simbólicos, respectivamente, conforme a observação de uma das formas de representação conceitual listadas anteriormente.

Após essa etapa descritiva do trabalho, passou-se à fase de interpretação dos dados obtidos. Tal fase foi subsidiada, quando pertinente, por informações encontradas em outros elementos presentes na capa - como nas chamadas, especialmente aquelas relacionadas às imagens - e mesmo no interior da edição investigada, principalmente pelas que diziam respeito às participantes representadas, contidas em reportagens sobre tais participantes. Enfatize-se, no entanto, que a abordagem desses elementos é complementar, uma vez que o foco do trabalho são as representações construídas pelo componente visual. Em um nível mais amplo, procurou-se identificar discursos evocados pelos significados textuais das capas e relacioná-los ao que pesquisas sociais apontam como características do modelo de relações raciais brasileiro. Os resultados desse processo encontram-se esquematizados para cada uma das capas investigadas, na seção que segue, ao longo da análise.

Na seção seguinte, portanto, são apresentadas a análise e a discussão dos dados.

\section{ANÁLISE E DISCUSSÃO DOS DADOS}

\subsection{Análise}

A capa da edição de novembro de 1996 apresenta os atores sociais ${ }^{3}$ Taís Araújo e Zezé Motta como participantes representados (FIG. 3). Em 1996, Taís Araújo tinha 17

\footnotetext{
3 Neste trabalho, optou-se pelo uso do termo 'ator social' como tradução de 'social actor', independentemente do sexo do participante representado. Tal decisão foi motivada pela constatação de que o termo 'atriz', no português do Brasil, está fortemente vinculado à profissão.
} 
anos e havia sido escalada para representar Xica da Silva, em novela homônima. De acordo com reportagem da revista, ela foi a primeira protagonista negra na história da televisão brasileira. Esse foi seu segundo trabalho na TV, mas Taís Araújo já havia atuado no teatro. Além disso, ela integrava, na época, o casting de duas conceituadas agências de modelo. Zezé Motta, ao contrário de Taís Araújo, já era uma atriz experiente em 1996: começou sua carreira no final da década de 60 e atuou no cinema, no teatro e na televisão. Naquele momento, ela representava a mãe de Xica da Silva na novela estrelada por Taís Araújo, depois de ter representado a própria protagonista no cinema. Além de atriz reconhecida, Zezé Motta também é cantora e militante da causa negra.

Quanto aos significados representacionais, a análise da imagem que compõe a capa da edição de 1996 indica que sua estrutura é conceitual. A imagem apresenta um processo classificacional, caso em que é possível identificar Superordenados, em relação ao qual são posicionados os participantes Subordinados. Como os Superordenados são indicados pelo contexto/co-texto e inferidos a partir da similaridade entre as participantes representadas, tem-se uma taxonomia fechada. No caso em questão, as participantes representadas, Zezé Motta e Taís Araújo, podem ser consideradas como Subordinadas a mais de uma classe simultaneamente: em relação à nacionalidade (brasileiras), ao grupo racial (negras), ao gênero social (mulheres) e à profissão (atrizes). Têm-se, então, quatro Superordenados, sendo que os dois primeiros podem ser identificados a partir do slogan que identifica a publicação - "A revista dos negros brasileiros". A ênfase, no caso de uma revista direcionada a esse público, parece estar no fato de as duas pertencerem ao mesmo grupo racial.

Além dos aspectos em comum entre as duas participantes representadas apontados anteriormente, é possível também pensar no fato de que ambas representaram a mesma personagem na ficção, Zezé no cinema e Taís na TV. Eis um traço em comum que pode ser identificado na chamada "Taís Araújo e Zezé Motta: A força de Xica da Silva". Tal referência a essa personagem histórica e a sua representação midiática pode ser interpretada como uma tentativa de se estabelecer uma identificação positiva para os leitores, se, assim como conclui Rossini (1997) ao analisar o filme Xica da Silva, pensarse a personagem como um ícone da luta do negro contra a aculturação e a dominação e da luta pela liberdade. Por outro lado, a identificação dos leitores com a representação que se faz nas telas pode gerar um efeito negativo, uma vez que, de acordo com o que se retrata no filme (e que pode ser estendido à trama televisiva), Xica só teria saído da condição de escrava e ascendido socialmente em virtude de seus "talentos eróticos" (RODRIGUES, $1988^{4}$ apud ROSSINI, 1997). Assim, a referência poderia reforçar o estereótipo do negro como naturalmente luxurioso, estereótipo este que, de acordo com Conceição (1996), constitui um dos três "ll" (eles) por meio dos quais a mídia acostumou-se a representar o negro: lúgubre, lúdico e luxurioso.

Paralela a essa estrutura classificacional, é possível distinguir outro tipo de estrutura conceitual na imagem em questão, por meio da observação da cor das roupas usadas pelas participantes representadas. Nesse caso, identifica-se um processo simbólico atributivo, uma vez que o valor simbólico atribuído às cores verde e amarelo, os Atributos simbólicos,

${ }^{4}$ RODRIGUES, J. C. O negro brasileiro e o cinema. Rio de Janeiro: Globo, 1988. 
representa um aspecto da identidade de Taís Araújo e de Zezé Motta, as Portadoras, a saber, sua brasilidade.

Elementos conflitantes na imagem da capa de 1996, no que diz respeito aos significados representacionais, são a subordinação de Taís Araújo e de Zezé Motta à brasilidade e a um grupo racial comum, o dos negros, embora a primeira apresente tom de pele e traços que poderiam afastá-la de uma classificação como negra, na hipótese de se tomar como base o discurso da democracia racial que acentua especialmente diferenças de tom de pele para uma elegia à mistura racial brasileira. Magalhães (2004: 37) denomina "estetização das identidades raciais" o uso da cor em detrimento da origem cultural para classificar grupos raciais, processo este que contribui para a invisibilidade da questão da raça, na medida em que reforça o mito da democracia racial e, com ele, a beleza e a harmonia da mistura de raças no Brasil. Em um contexto de classificação racial complexa, como é o do Brasil ${ }^{5}$, pode-se especular se seria por essa razão que Taís foi modelo e Zezé não, ou se a ênfase na brasilidade das participantes representadas, no contexto discursivo mais amplo de relações raciais, se associaria ao apagamento da herança cultural africana. Nesse sentido, cabe notar também que Taís Araújo, na capa sob análise, traz os cabelos alisados, o que pode ser interpretado como uma atitude de desvalorização do padrão estético dos negros.

Na FIG. 3, apresentam-se sinteticamente os significados construídos pela imagem da capa de novembro de 1996:

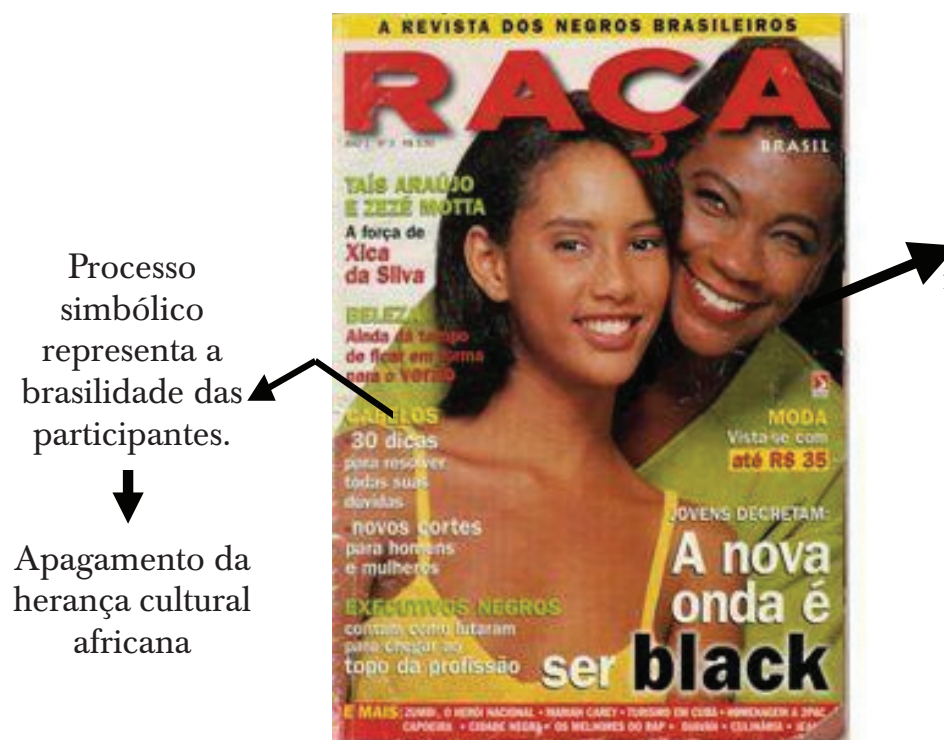

\section{Processo classificacional representa Taís} Araújo e Zezé Motta como pertencentes ao mesmo grupo racial, apesar do tom de pele mais claro e dos traços faciais mais próximos do padrão ocidental hegemônico da primeira.

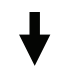

Fortalecimento do grupo

FIGURA 3 - Significados representacionais na capa de Raça Brasil de 1996

\footnotetext{
${ }^{5}$ Para mais detalhes, cf. Magalhães (2004, 2006).
} 
No que segue, apresenta-se a análise da capa da edição da revista Raça Brasil de novembro de 1998. Tal capa traz Keli Cristina e Sacramento como participantes representados (FIG. 4). Trata-se de modelos das agências Mega e Elite, respectivamente.

No que diz respeito aos significados representacionais, observa-se que a imagem que compõe a capa em questão apresenta uma estrutura complexa, uma vez que nela se identificam uma estrutura narrativa e uma conceitual. Quanto à primeira, é possível distingui-la a partir do vetor que é formado pela posição dos braços de Keli Cristina, o Ator, ao abraçar, por assim dizer, Sacramento, a Meta. Nesse caso, tem-se um processo de ação transacional unidirecional, que representa a figura feminina como ativa e com uma atitude direcionada à figura masculina. Apesar de este não ser o foco deste trabalho, vale comentar que tal representação parece remeter a um discurso sexista que postula que a mulher deve agir para e em função do homem, ao mesmo tempo em que parece corroborar a imagem daquela como protetora. Quanto à estrutura conceitual, observa-se aqui um processo classificacional, em que os participantes representados encontram-se subordinados a três Superordenados: um relacionado a seu grupo racial, já que ambos são negros; outro relacionado à sua profissão, uma vez que ambos são modelos; e um terceiro, relacionado à nacionalidade, pois ambos são brasileiros. Como tais Superordenados podem ser recuperados por inferência, a partir das similaridades entre os participantes Subordinados e pelo contexto/co-texto da revista (em especial pelo slogan da publicação, principalmente no caso do último Superordenado), tem-se uma taxonomia fechada.

Algo que chama a atenção na imagem em questão é a apresentação dos participantes representados com o corpo quase nu. E, nesse caso, o que ficou mais à mostra foi o corpo de Keli Cristina, que, ao abraçar Sacramento, esconde uma parte do corpo deste, evidenciando o seu - configuração que parece indicar uma maior exploração da sensualidade feminina. Essa exposição enfatiza a cor da pele dos participantes representados, ênfase que remete à já mencionada estetização das identidades raciais apontada por Magalhães (2004) e que parece ir ao encontro da chamada mais saliente ${ }^{7}$ da capa de 1998, que traz como oração mais proeminente a que afirma "nossa cor é linda!". Tal oração parece ecoar a ideologia do "black is beautiful" movimento cultural dos anos 60 nos Estados Unidos que ressaltava a beleza do padrão estético negro. O objetivo era promover a valorização, especialmente, do cabelo dos afro-descendentes, incentivando-os a assumi-los - postura esta que parece ser incentivada por meio dos elementos acima mencionados.

Tais observações conduzem à identificação de outro tipo de processo conceitual na imagem dessa capa para além do processo classificacional mencionado anteriormente. É possível distinguir nesta um processo analítico, em que Keli Cristina e Sacramento são os Portadores e em que é realçada a cor de sua pele como um Atributo Possessivo. A reduzida exploração da profundidade e das cores, o segundo plano neutro e a forte ênfase na pele dos participantes representados contribuem para a realização desse processo, o qual, inclusive, colabora com sua classificação como integrantes do grupo dos negros e auxilia na promoção da estetização da raça.

${ }^{6}$ A saliência, um conceito referente aos significados composicionais, diz respeito ao grau de importância conferido a determinado elemento da composição. A saliência é analisada com base em diversos fatores, como o tamanho, o foco, o contraste de tom e de cor, dentre outros. 
Outro ponto interessante no que diz respeito à configuração da imagem sob análise merece ser ressaltado: nota-se que, tanto no que diz respeito à simulação de nudez quanto no que concerne à pose dos participantes, a composição da imagem parece reforçar os já mencionados discursos que representam o negro como sendo inerentemente sensual e luxurioso, especialmente no que diz respeito à mulher negra, nesse caso em destaque. Além disso, a forma de representação escolhida parece legitimar a imagem do Brasil como um lugar onde a sexualidade aflora livre e naturalmente.

A FIG. 4 sintetiza os significados construídos pela imagem sob análise na capa de novembro de 1998:

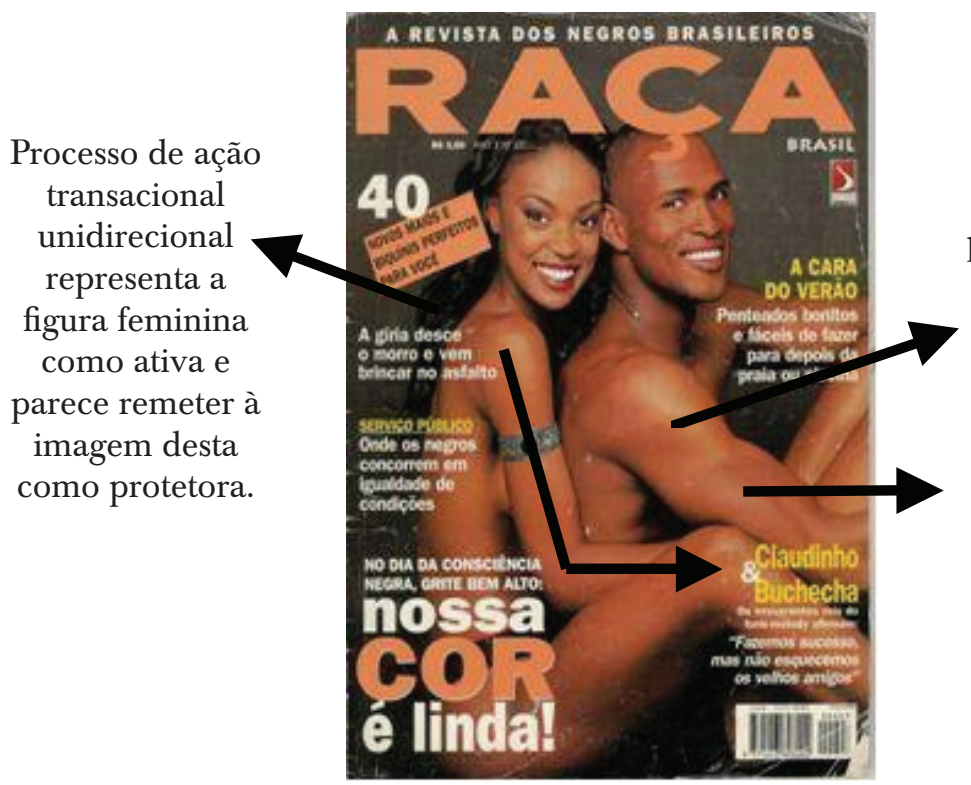

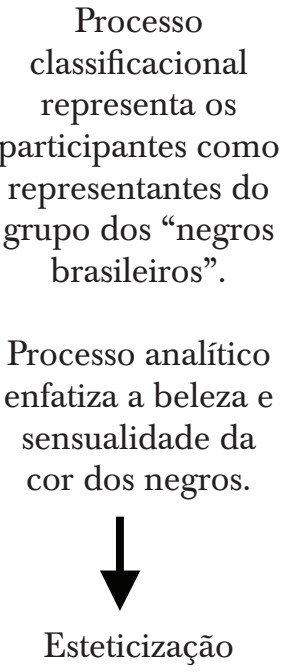
representa os participantes como representantes do grupo dos "negros brasileiros". Processo analítico enfatiza a beleza e sensualidade da cor dos negros.

FIGURA 4 - Significados representacionais na capa de Raça Brasil de 1998

A seguir, é feita a análise dos significados construídos pela capa da edição de 2004 da revista Raça Brasil, que traz Isabel Fillardis como participante representada (FIG. 5). A reportagem da revista que traz o perfil dessa participante afirma que esta iniciou sua carreira como modelo, mas que, após passar em um teste para a oficina de atores da Rede Globo, teve sucesso como atriz e provou "que tinha mais predicados do que um mero rosto bonito". Além de ressaltar a determinação e otimismo de Isabel Fillardis, a reportagem enfatiza seu engajamento social e menciona atitudes cidadãs por ela adotadas.

Quanto aos significados representacionais, a imagem da capa sob análise apresenta uma estrutura simples, em que se distingue somente uma estrutura conceitual. Observase um processo analítico, em que Isabel é o Portador, e são realçados seus Atributos 
Possessivos - a pele, o cabelo, os traços realçados pela maquiagem, seus acessórios. A participante posa para a foto como se para um catálogo de moda. Mas, nesse caso, é a própria Isabel e alguns de seus 'predicados' que se dão à vista. Percebe-se, aqui, uma forte exploração do sistema do olhar, que contribui para a realização de significados interativos, os quais não serão abordados neste trabalho.

No caso em questão, ao contrário do que se verifica nas imagens das capas analisadas anteriormente, não se identifica um processo classificacional que posicione Isabel Fillardis como subordinada ao grupo dos negros. Mas seus Atributos Possessivos parecem realizar essa classificação e podem ser lidos, simultaneamente, como valorização de traços negros, como os cabelos e a pele, por parte da revista e da participante representada e como ênfase na apresentação de Isabel Fillardis também como modelo. Representa-se, assim, Isabel como negra e, ao mesmo tempo, como um exemplo do construto da estetização racial.

A FIG. 5 apresenta esquematicamente os significados construídos pela imagem sob análise na capa de novembro de 2004:

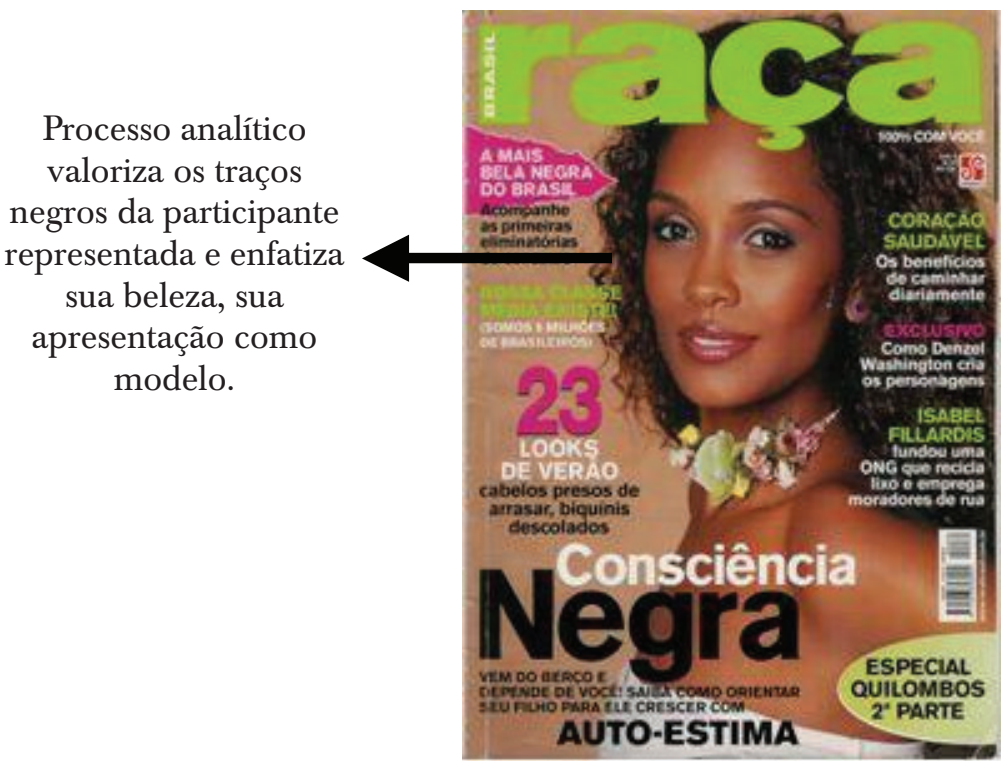

FIGURA 5 - Significados representacionais na capa de Raça Brasil de 2004

A última análise apresentada neste trabalho tem como foco a capa da edição de Raça de 2006, que traz como participante representada Liliane de Carvalho, popularmente conhecida como Negra Li (FIG. 6). Há anos na carreira de cantora, Negra Li estreou como atriz no final de 2006, interpretando uma das componentes de uma banda de rap na série Antônia, exibida pela Rede Globo, e no longa-metragem de mesmo nome.

No que diz respeito aos significados representacionais, a imagem que compõe a capa da edição de Raça de 2006 apresenta uma estrutura complexa, composta por uma estrutura narrativa e por uma estrutura conceitual. Quanto à primeira, nota-se a existência de apenas 
uma participante, Negra Li, o Ator, de quem parte um vetor formado pela posição de seus braços e mãos. O gesto da participante representada pode ter uma dupla interpretação. É possível pensar que ela esteja realizando um passo de hip hop, o que configuraria um processo de ação não-transacional, passível de ser textualizado na linguagem verbal como 'Negra Li dança', por exemplo. Alternativamente, é possível entender tal gesto como uma espécie de processo de ação transacional bidirecional, em que a mesma participante seria ora o Ator, ora a Meta, estrutura que equivaleria, por exemplo, a uma oração como 'Negra Li se mostra' ou 'Negra Li se apresenta'. Nesse caso, ter-se-ia uma ação da participante representada voltada para ela mesma, uma espécie de 'voz reflexiva' visual, tipo de representação não conceituada por Kress e van Leeuwen (1996). Além desta, é possível observar outra estrutura narrativa na imagem em questão: nota-se que Negra Li entreabre os lábios, mas não sorri, configuração visual que pode ser vista como um processo de fala e que poderia ser textualizada verbalmente como 'Negra Li canta' ou 'Negra Li conta sua história'. Nesse caso, Negra Li seria o Dizente, e, como não se reproduz o conteúdo da fala da participante, o processo não estaria projetando um Enunciado, situação que também não é contemplada por Kress e van Leeuwen (1996).

No que diz respeito à estrutura conceitual da imagem em questão, é possível distinguir nesta um processo analítico, em que Negra Li é o Portador e são realçados Atributos Possessivos, como seus acessórios, seus traços faciais ressaltados pela maquiagem e, embora em menor grau, por estarem relativamente escondidos pelo título da publicação, os cabelos crespos da participante. Este processo parece contribuir para a classificação de Negra Li como pertencente ao grupo dos negros, ao destacar seu cabelo e seus acessórios, que remetem ao estilo das negras africanas.

Na FIG. 6, sumarizam-se os significados construídos pela imagem da capa de novembro de 2006:

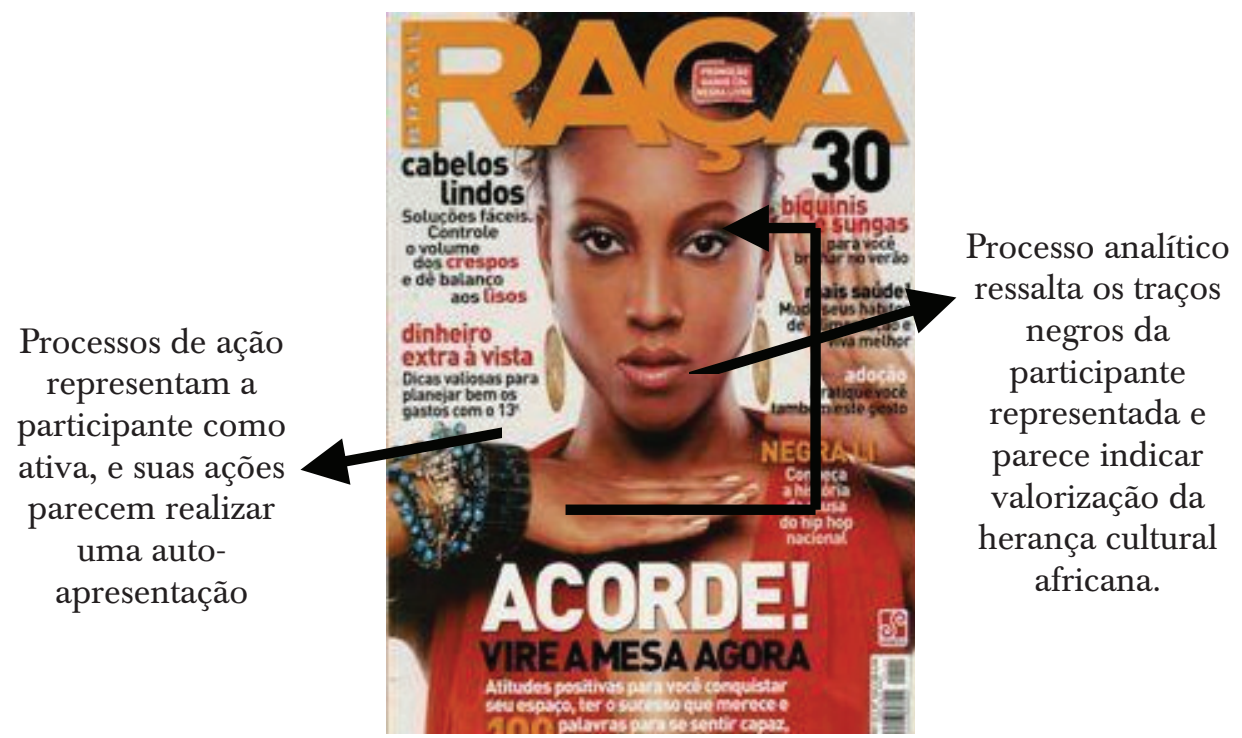

FIGURA 6 - Significados representacionais na capa de Raça Brasil de 2006 
$\mathrm{Na}$ seção a seguir, apresenta-se a discussão dos significados representacionais construídos pela capa das edições do corpus.

\subsection{Discussão dos dados}

Analisando os significados representacionais da imagem da capa das edições de Raça que compõem o corpus, é possível identificar traços em comum e, ao mesmo tempo, traços distintos, no que diz respeito a determinados aspectos.

Observa-se que todas as capas apresentam uma estrutura conceitual, que, de forma geral, realiza ou enfatiza a identificação dos participantes representados ao grupo dos negros. Isso mostra que a representação dos atores sociais que figuram na capa da revista como integrantes desse grupo é uma constante, o que já se poderia esperar em uma revista cujo slogan, em seus primeiros anos de publicação, a identifica como "A revista dos negros brasileiros". Tal representação, no entanto, parece se revestir de especial importância quando se apresentam na capa pessoas que, no contexto brasileiro, poderiam não ser classificadas como negras. É o caso, por exemplo, de Taís Araújo, na capa da edição de 1996, a qual, por ter um tom de pele 'mais claro' e traços faciais aparentemente mais próximos de um padrão ocidental hegemônico, possivelmente seria dissociada do grupo dos negros, como mencionado anteriormente (cf. noção de estetização de MAGALHÃES, 2004). Desse modo, pode-se argumentar, a revista realiza um movimento no sentido de incluir nesse grupo pessoas que, dadas a gama de classificações diferentes de cor de pele na cultura, poderiam ser classificadas como não pertencentes a ele, de modo a fortalecê-lo. Tal preocupação é identificada não somente no período inicial da publicação, mas também na capa da edição de 2004, representativa de um período mais recente. No entanto, nesta edição, o fato de se representar exclusivamente uma participante que, se comparada a atores sociais representados nas capas das demais edições do corpus, apresenta traços faciais mais próximos de um padrão ocidental hegemônico pode contribuir para a acentuação do preconceito, como aponta D’Adesky (2001: 47), que entende esse fenômeno como uma forma de exclusão baseada em critérios fenotípicos.

As edições de 1996 e de 2004 possuem somente estrutura conceitual. A ênfase, em 1996, parece recair especialmente sobre a identificação de Taís Araújo como negra e, portanto, no fortalecimento do grupo dos negros, e na representação da brasilidade das participantes, que se realiza, visualmente, por meio de um processo simbólico e por meio de um processo classificacional. Vale comentar que a questão da brasilidade pode ser observada também no slogan da publicação nos seus anos iniciais ("A revista dos negros brasileiros"). Tal ênfase nesse aspecto da identidade dos participantes do ato comunicativo parece remeter à supressão da herança cultural africana, no contexto discursivo brasileiro mais amplo. Outro aspecto que merece destaque na capa da edição de 1996 é a referência a Xica da Silva na chamada relacionada à imagem das participantes representadas, referência que, a depender da forma de interpretação dessa personagem histórica, pode resultar em uma identificação positiva ou negativa por parte dos leitores.

Nas capas de 1998 e 2006, o processo conceitual analítico, de forma geral, parece contribuir para a realização da classificação dos participantes representados como negros, classificação que, em 1998, também se realiza por meio de um processo classificacional. 
No caso desta edição, a representação racial parece estar fortemente associada a traços fenotípicos, especialmente à questão da cor, o que, de certa forma, parece ir de encontro aos significados construídos na capa da edição de 1996, a qual, ao incluir Taís Araújo no grupo dos negros, sugere uma rejeição ao critério fenotípico. Entretanto, levando-se em consideração os significados construídos pela chamada mais saliente da capa desta edição (“Jovens decretam: A nova onda é ser black"), observa-se, paradoxalmente, a valorização desse critério, na medida em que se evoca a ideologia do "black is beautiful". Tal evocação pode ser identificada também na capa da edição de 1998, tanto por meio da imagem, que enfatiza a cor dos participantes representados, quanto por meio da chamada "No dia da Consciência negra, grite bem alto: nossa cor é linda!". Desse modo, é possível argumentar que, nas edições representativas do período inicial da revista, a evocação do "black is beautiful", ao remeter à "estetização da identidade racial" (MAGALHÃES, 2004, 2006), exalta a beleza e a harmonia da mistura de raças no Brasil e contribui para reforçar o mito de que existe uma democracia racial no país.

$\mathrm{Na}$ edição de 2006, observa-se que o processo analítico propicia a associação do estilo de Negra Li ao das negras africanas, o que parece indicar a valorização dessa herança. Ressalte-se também que, tanto em 2004 quanto em 2006, não se identifica na capa o slogan que aponta para a questão da brasilidade. Assim, parece haver a representação de discursos conflitantes nos dois períodos sob análise no que diz respeito à incorporação e valorização da herança cultural africana: enquanto mais recentemente parece haver essa valorização, no período inicial a ênfase parece ser na brasilidade.

Em 1998 e 2006, há a representação de participantes como ativos. Porém, essa representação realiza-se de forma diferente na edição de 1998, representativa do período inicial da revista, se comparada àquela referente a um período mais recente. Na primeira, o papel de Ator é conferido à figura feminina, que, no entanto, age em função do homem. Nesse caso, a imagem parece evocar um discurso sexista. Vale lembrar que, nessa mesma edição, a simulação de nudez dos participantes representados remete a discursos preconceituosos que constroem a imagem de negros e negras como pessoas de sexualidade aguçada, principalmente no que diz respeito à figura feminina, nesse caso mais exposta. Já na edição de 2006, a participante representada não tem sua ação direcionada a uma Meta, agindo sobre si mesma. Desse modo, representa-se a figura desta como independente, autônoma para atuar, adotando "atitudes positivas" em favor de si própria, o que é sugerido pela associação que se parece estabelecer entre a chamada mais saliente da capa - “Acorde! Vire a mesa agora. Atitudes positivas para você conquistar seu espaço, ter o sucesso que merece e 100 palavras para se sentir capaz, digno, majestoso e vencedor" - e a imagem da participante. Assim, a edição de Raça de 2006, representativa de um período mais recente, parece convidar seu público a adotar uma postura mais ativa e afirmativa, por meio de sua identificação com a representação dessa participante.

Analisando conjuntamente a capa de todas as edições do corpus quanto à imagem, observa-se a existência de uma taxonomia e, portanto, de um processo classificacional. Haveria, nesse caso, um Superordenado, que parece apontar uma tendência da revista no que diz respeito aos critérios para a seleção dos atores sociais que compõem a capa. Tal Superordenado está relacionado à questão da ascensão social: os participantes representados na capa das edições analisadas são pessoas (re)conhecidas, que ascenderam 
socialmente, por meio de seu trabalho, e/ou midiáticos - tendência esta que se confirma ao se observar os atores sociais representados em outras capas da publicação em questão. É possível pensar que o objetivo da publicação é representar pessoas que constituem um ponto de identificação positiva para os leitores, identificação que se busca realizar visualmente, em todas as capas analisadas, principalmente por meio do olhar dos participantes representados, que sempre se direciona ao observador. No entanto, o sistema do olhar, que é analisado no âmbito dos significados interativos, não constituiu foco de análise aqui e seria objeto de um estudo futuro.

\section{CONSIDERAÇÕES FINAIS}

O presente trabalho buscou analisar os significados representacionais realizados por meio da imagem da capa das edições de novembro de 1996, 1998, 2004 e 2006 da revista Raça Brasil. A pesquisa foi norteada pelas seguintes perguntas de pesquisa: (1) como o modo semiótico visual atua na construção das representações de identidades raciais nas capas sob análise? (2) há mudanças em tais significados ao longo do eixo temporal analisado?

$\mathrm{O}$ arcabouço descritivo da gramática do design visual, mais especificamente no que se refere às estruturas representacionais mostrou-se eficaz para a abordagem do corpus em questão sob a perspectiva de tais perguntas.

Foram observados diferentes significados representacionais nas capas das edições analisadas, o que parece estar relacionado a propósitos distintos ou à assimilação pela revista de determinadas imagens dos negros - muitas vezes estereotipadas - em cada um dos períodos analisados. Em 1996, o uso de uma estrutura conceitual, a qual classifica e identifica Taís Araújo e Zezé Motta como pertencentes ao grupo dos negros, a despeito dos traços fenotípicos aparentemente mais próximos do padrão ocidental hegemônico da primeira, pode estar relacionado a um propósito político de fortalecimento desse grupo racial, por meio da agregação a este de pessoas antes não classificadas como negras - o que está diretamente associado à questão da consciência negra. Na capa de 1998, a forma de representação visual escolhida parece ecoar o estereótipo dos negros como pessoas com a sexualidade aguçada, e a ênfase na raça como relacionada a traços fenotípicos, especialmente à cor da pele, remete à "estetização das identidades raciais" definida por Magalhães (2004, 2006). Segundo D’Adesky (2001), o uso de critérios fenotípicos para a classificação racial pode levar à exclusão de negros que apresentam um padrão de beleza diferente do padrão ocidental hegemônico, o que parece ocorrer nas edições de Raça de 2004 e de 2006, uma vez que, na capa destas, representam-se visualmente somente negras que apresentam traços faciais mais próximos desse padrão, se comparadas a atores sociais representados nas capas das outras edições. Tal exclusão, no que diz respeito às referidas edições, parece contradizer a afirmação de D’Adesky (2001:97) de que a revista Raça Brasil, ao representar "mulheres negras de cor escura, nariz achatado e cabelo carapinha", contrariava a tendência da mídia brasileira de excluí-las. Por outro lado, nas edições mais recentes, pode-se pensar em um movimento em direção à valorização do grupo, por meio, por exemplo, da representação dos cabelos de Isabel Fillardis e de Negra Li. Nesse sentido, 
a apresentação visual desta participante representada parece sugerir uma valorização da herança cultural africana. Além disso, a representação da participante da capa de 2006 como aparentemente independente e ativa pode estar relacionada à construção da autoestima, que gera a mobilização e que, por sua vez, constrói e representa a consciência do leitor.

Por um lado, pode-se deduzir que há um movimento no sentido de promover/ fortalecer a auto-estima e a consciência negra dos leitores, presumivelmente negros, ao se representar, tanto por meio das imagens quanto por meio de chamadas da capa da revista, atores sociais negros que ascenderam, ganhando visibilidade em uma instituição que se funda em torno de hegemonias como a mídia. Taís Araújo, negra e na época com apenas 17 anos, protagonizava a novela Xica da Silva: ela foi a primeira protagonista negra da história da TV. Zezé Motta e Isabel Fillardis eram atrizes negras reconhecidas à época das respectivas publicações em que figuram. Keli Cristina e Sacramento são modelos de agências reconhecidas, a saber, Mega e Elite. E Negra Li, embora no início de sua carreira como atriz, vem conquistando cada vez mais espaço na mídia. Por outro lado, a escolha dos participantes representados visualmente nas capas parece respaldar críticas de que a revista incentiva o individualismo e o voluntarismo, independente das condições que impedem os negros de ascender socialmente (ALMADA, 2002).

Para finalizar, cabe mencionar as limitações deste trabalho. O corpus utilizado, composto por apenas quatro edições da revista Raça Brasil, aponta tendências e permite que se teçam considerações a respeito da publicação, mas impede que se façam generalizações a seu respeito. Além disso, vale ressaltar a escolha por se abordar somente a capa de cada edição, por enfatizar a análise da imagem e por enfocá-la apenas quanto à sua estrutura representacional. Desse modo, sinaliza-se aqui a pertinência de se aprofundar a investigação das representações construídas/evocadas pela revista $R a c ̧ a$, por meio da inclusão de outras edições, de outros textos da revista e da ampliação do foco da análise. Seria pertinente também uma análise comparada, inserindo no corpus edições de revistas direcionadas a um público-alvo segmentado de outro ponto de vista que não o racial. Tal trabalho é essencial para a compreensão e para um possível aprimoramento de uma publicação especialmente importante em um contexto em que prevalece a invisibilidade dos negros ou a depreciação de sua imagem - como é o caso do contexto midiático brasileiro.

\section{REFERÊNCIAS BIBLIOGRÁFICAS}

CONCEIÇÃO, F. (1996). Mordendo um cachorro por dia. No Brasil a mídia retrata a imagem do negro com três "ll”: lúgubre, lúdico e luxurioso. In: MUNANGA, Kabengele. (Org.) Estratégias e políticas de combate à discriminação racial. São Paulo: Editora da Universidade de São Paulo, p. 253-259.

D’ADESKY, J. (2001). Pluralismo étnico e multiculturalismo: racismos e anti-racismos no Brasil. Rio de Janeiro: Pallas, 248 p.

HALLIDAY, M. A. K. (1978). Language as Social Semiotic. London: Edward Arnold, 256 p.

HEBERLE, V. M. (2004). Revistas para mulheres no século 21: ainda uma prática discursiva de consolidação ou de renovação de idéias? Linguagem em (Dis)curso - LemD, Tubarão, v. 4, Especial, p. 85-112. 
Cadernos de Estudos Lingüísticos, Campinas, 53(1), Jan./Jun. 2011

HODGE, R.; KRESS, G. (1988). Social Semiotics. Ithaca, New York: Cornell University Press, 285 p.

JEWITT, C.; OYAMA, R. (2001). Visual Meaning: a Social Semiotic Approach. In: VAN LEEUWEN, T.; JEWITT, C. Handbook of Visual Analysis. London, Thousand Oaks; New Delhi: Sage Publications, p. 134-156.

KRESS, G.; VAN LEEUWEN, T. (1996). Reading images: The Grammar of Visual Design. London; New York: Routledge, $288 \mathrm{p}$.

KRESS, G.; LEITE-GARCIA, R.; VAN LEEUWEN, T. (1997). Discourse Semiotics. In: VAN DIJK, T. Discourse as Structure and Process. London; Thousand Oaks; New Delhi: Sage Publications, p. 256291.

MAGALHÃES, C. M. (2004). Interdiscursividade e conflito entre discursos sobre raça em reportagens brasileiras. Revista Linguagem em (Dis)curso - LemD, Tubarão, v. 4, Especial, p. 35-60.

. (2006). A critical discourse analysis approach to news discourses and social practices on race in Brazil. D.E.L.T.A., São Paulo, v. 22, n. 2, p. 275-301. Disponível em: <http://www.scielo.br/scielo. php?script=sci_arttext\&pid=s0102-44502006000200003\&lng=en\&nrm=iso>. Acesso em: 19 abr. 2007.

MEDEIROS, H.; AJZENBERG, B.; OLIVEIRA, E. H. P. de; LEITÃO, M.; ALMADA, S. (2002). A imprensa e o racismo. In: RAMOS, S. (Org.). Mídia e racismo. Rio de Janeiro: Pallas, p. 26-58.

PINHEIRO, V. S. (2007). Analisando significados de capas da Revista Raça Brasil: um estudo de caso à luz da semiótica social. Belo Horizonte, FALE/UFMG. (dissertação de mestrado).

REVISTA RAÇA BRASIL. (1996). São Paulo: Editora Símbolo, n. 3, nov. , 114 p.

REVISTA RAÇA BRASIL. (1998). São Paulo: Editora Símbolo, n. 27, nov. , 122 p.

REVISTA RAÇA BRASIL. (2004 ). São Paulo: Editora Símbolo, n. 80, nov. , 98 p.

REVISTA RAÇA BRASIL. (2006 ). São Paulo: Editora Símbolo, n. 104, nov. , 98 p.

ROSSINI, M. S. (1997). Xica da Silva e a luta simbólica contra a ditadura. O olho da história, Salvador, n. 4. Disponível em: <http://www.oolhodahistoria.ufba.br/04rossin.html>. Acesso em: 21 out. 2010.

VAN LEEUWEN, T. (1996). The Representation of Social Actors. In: CALDAS-COULTHARD, C. R.; COUThard, M. (Eds.). Texts and Practices: Readings in Critical Discourse Analysis. London; New York: Routledge, p. 32-70.

(2005). Discourse. In: VAN LEEUWEN, T. Introducing Social Semiotics. London; New York: Routledge, p. 93-116. 